\title{
Notes on general format, dates, and transliteration
}

The world of medieval Islam is both foreign and familiar to the Western reader: foreign, in that most of its literature, whether prose or poetry, remains untranslated and often even unedited; yet familiar, because of the shared history which has tied the fates of the Islamic and the Christian worlds closely together for centuries. In the arrangement of this book, we have endeavoured to find ways to bring this foreign world to the reader of English as much as possible. For this reason, we have translated virtually everything: not only the quotations from various sources in a whole host of languages such as Arabic, Persian, Syriac, and Hebrew, but also the titles of the many essays, epistles, and encyclopedias discussed here. Similarly, the bibliography favours recent English literature, although we also thought it desirable to provide some references to works of scholarship and sources in other European languages. Since our essay is often based on material inaccessible to the general reader, and since we advance some new theses and interpretations, we thought it desirable to provide the necessary documentation, especially to sources hitherto unpublished.

In order to reconcile these two exigencies, readability and scholarly rigour, we have opted for the following system. Before the note section to each chapter, there is a short bibliographical essay providing suggestions for further general reading on the topics covered in that chapter. A separate full bibliography lists all the literature in English and other European languages cited in the endnotes. The Index of names and works enumerates the authors and their treatises that we discuss; in addition, it also contains the names of all historical personalities to which we refer. Because there are no standard English designations for most of our primary sources, we give, in the Index, both the English titles which we have adopted and the Arabic originals. Since such Arabic titles often rhyme, some of their beauty may even be appreciated in transliteration. Moreover, in the Index the reader can also find references to translations as well as editions, when such have been published.

For the purpose of not cluttering the volume, the references to Arabic editions in the Index are, where possible, abbreviated according to the scholarly 
conventions laid down by Manfred Ullmann in his monumental Dictionary of Classical Arabic (Wörterbuch der Klassischen Arabischen Sprache). Where there are no standard abbreviations, we provide the necessary information after the Arabic title. Specialists should have no trouble locating the primary sources which we cite, while those coming to the subject for the first time will find the translations to be a useful guide.

For convenience, all dates given in the body of the text are those of the Christian calendar, unless otherwise specified. The designation $\mathrm{AD}$ is used only when there is need to distinguish a date from an earlier BC date. General references to a century rather than a specific year refer to centuries of the Christian era. For example, ninth century refers to years AD 800-99 (which in the Muslim calendar would be $184-287$ ). The Muslim calendar is designated by $\mathrm{H}$; it is a lunar one of 354 days beginning from the day of the Emigration (Hijrah) of the Prophet Muhammad from Mecca to Medina, which occurred on I6 July 622 of the Christian calendar. Consequently, Muslim dates do not correspond directly to those of the Christian era (AD) commonly used today in Europe and the Americas (and sometimes called Common Era).

We have transliterated Arabic according to a system which readers of English should find relatively easy. A dot under the letters $d, s, t$, , and $z$ means that they are pronounced in an 'emphatic' way, that is to say a bit deeper and more sombre. An $h$ with a dot is articulated as a heavily aspirated $h$, whilst th and $d h$ are respectively an unvoiced ('think') and voiced ('there') 'th' in English; the combination $k h$ is pronounced like gh in Scotland as for instance in the name 'Naughtie'. A macron above the vowels $\bar{a}, \bar{i}$, and $\bar{u}$ means that they are long and often stressed. 